\title{
How Can the Safety of Biotherapy Products be Ensured for Patients?
}

\author{
Hervé Brailly, ${ }^{1}$ Eric Postaire, ${ }^{2}$ Pierrette Zorzi $i^{3}$ and the Participants in Round Table \\ No. 3, Giens XIX \\ 1 Innate Pharma, Marseille, France \\ 2 INSERM-DAPS, Paris, France \\ 3 Afssaps, Saint-Denis, France
}

\section{Abstract}

The topic of the round table being very broad, it was agreed with the participants that the discussion should be focused on autologous cell therapy (CT) used in tissue repair, immunomodulation or gene transduction. Autologous CT is actually comprised of both very innovative procedures as well as of products used in routine clinical practice. In France, the regulatory framework for CT has now been finalised, underlining the fact that a CT product (CTP) is intrinsically linked to the process used in its preparation. The objective of this round table was to define the essential prerequisites for the development of therapies involving ex vivo cell preparations and, more specifically, to address the issues associated with patient safety during the course of product development. The different stages of CTP development were considered: (i) requirements for CTP manufacturing in order to guarantee product quality; (ii) nonclinical development, and selection of appropriate animal models to provide the proof of the concept and support the definition of CTP specifications; and (iii) clinical development and methodological specificities of CTP development. The specific problems associated with the use of ancillary therapeutic products (ATPs) during the development of a CTP were discussed. Actions were proposed to ensure long-term supply of ATPs, which may be a significant bottleneck for the development of CT in France. Eventually, new regulatory provisions will come into force in the area of biovigilance, and it was deemed necessary for healthcare and industry professionals to be appropriately involved in the implementation phase.

Keywords: cell therapy, autologous, development, prerequisite, ancillary therapeutic products, biomonitoring

\section{Introduction}

Autologous cell therapy (CT) is a group of cell preparation techniques that target tissue repair, immunomodulation or gene transduction, with the general concept of an ex vivo modification of the cell preparation prior to re-administration. This broad therapeutic field is comprised of both very innovative procedures implemented in clinical trials as well as of products that have been in routine use for several years, such as autologous haematopoietic stem cell preparations.

CT is a very dynamic field in France. To date, approximately 150 clinical trials involving either autologous $\mathrm{CT}$ and /or ex vivo gene-therapy (GT) trials have been registered with Afssaps (the French Health Products Safety Agency) [figure 1], most of them being sponsored by academic institutions. It is noteworthy that, despite CT being a very active field, the proportion of phase II/III clinical trials using cell preparations is lower in France than in the US.

The regulatory framework for cell therapy products (CTPs) has recently been finalised in France, but not in most other European countries. Directive 2001/83 allowed the use of CTPs as medications in certain cases. Other European directives currently being discussed will enable European harmonisation in the near future - a development that is eagerly awaited by the professionals in this field.

There are two different objectives in the initiation of CT clinical trials, depending on the sponsor. On the one hand, the clinical trials sponsored by the biopharmaceutical industry aim at the development of the CTP in view of large-scale production

$\dagger$ For a list of participants, please see the end of the article. 

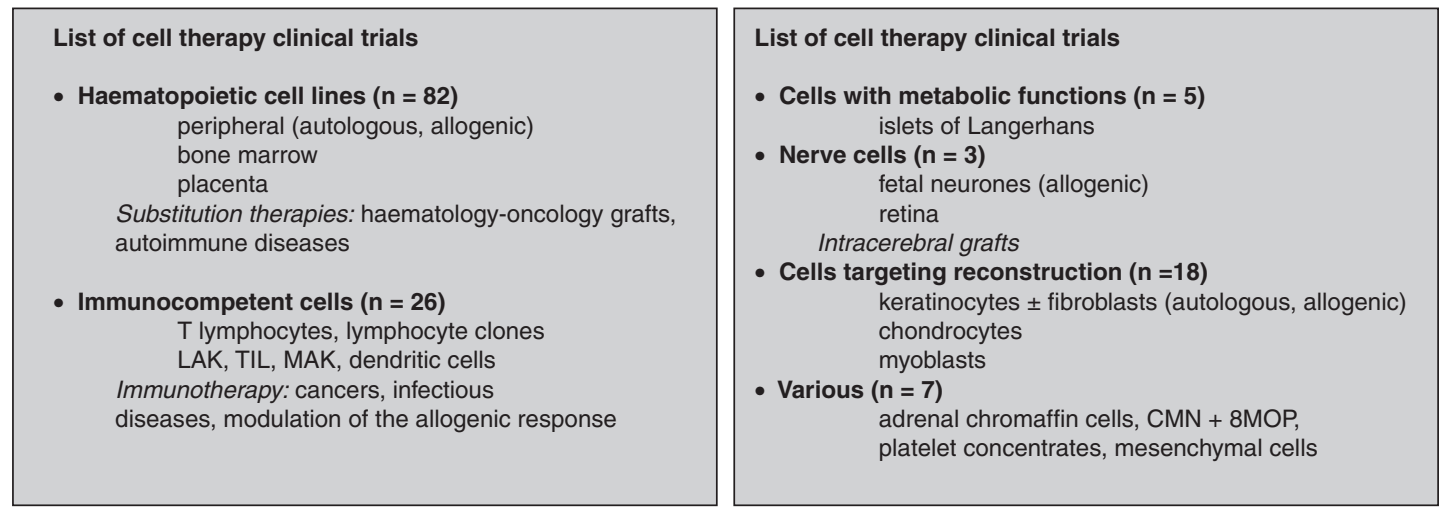

Fig. 1. Summary of all the cell therapy trials submitted to Afssaps (the French Health Products Safety Agency) since 1996 . CMN = mononuclear cells; LAK = lymphocyte activated killer; $\mathbf{M A K}=$ macrophage activated killer; 8MOP = 8-methoxy psoralene; $\mathbf{n}=$ number of trials; TIL = tumour infiltrating lymphocyte.

and product registration; on the other hand, the clinical trials initiated by academic teams aim primarily to establish experimental proof of a concept for a novel therapeutic approach. The difficulty with regard to the CT regulatory framework partly lies in the fact that these objectives are not identical. However, obtaining interpretable results in an exploratory clinical trial that aims to increase knowledge is obviously not possible without sufficient control over the reproducibility of the process and, even more importantly, without an appropriate guarantee of process safety. This applies to all trials, and all sponsors. Conversely, some other aspects of CT development (such as intellectual property rights, or supply of ancillary therapeutic products [ATPs] over the CTP lifetime) are not equally taken in account by the different groups of sponsors, namely those who aim to register their product/process and those who perform clinical trials to increase the knowledge base.

The focus of this round table was to formulate some general principles - applicable to all situations and all sponsors - for the development of autologous CTs, and possibly to identify unanswered questions on the basis of the development issues of quality, safety and efficacy.

\section{The Regulatory Framework}

The current regulations for CT in France are mainly based on three laws:

1. the 1994 Bioethics law which introduced the idea of "cell preparations'; ${ }^{[1]}$

2. the 1996 DMOSS law which classified CT and GT products in a new product category: 'Produits Biologiques à effet therapeutiques' (i.e. biological products for therapeutic use); ${ }^{[2]}$

3. the law of 1 July 1998 on the creation of Afssaps. ${ }^{[3]}$
This last law made Afssaps responsible for dealing with ATPs, organs, tissues, products of CT and GT, and biovigilance.

The publication of the Decree 2001-909 of 1 October 2001 ${ }^{[4]}$ specified the role of Afssaps and the procedures for issuing authorisations: (i) for institutions/organisations; (ii) for processes and products; and (iii) for clinical trials in the areas of CT and GT (figure 2). The provisions published on 3 February 2003, ${ }^{[5-7]}$ which finalised this Decree, specified the formats for the dossiers to be submitted to the Agency for each authorisation request.

\section{Quality of Cell Therapy Products: Control of the Process}

The definition of a CTP is intrinsically linked to the process used for cell preparation. A CT process can be divided into three key stages: (i) procurement; (ii) preparation and packaging; and (iii) administration to the patient. It must be controlled throughout the production chain. The control of the final stages and of related logistics are particularly important when multicentre trials are involved. To ensure a good control of product quality, the principles of Good Manufacturing Practice (GMP) must first be implemented at the manufacturing site. This applies to the premises, materials and staff training; quality assurance (QA) procedures should also be in place. This is already the case in some pilot centres in France.

The main specifications of the CTP must be roughly defined from the very start of the development, based on the final use for the CTP (metabolic, reconstructive, immunological, etc.). The specifications are likely to evolve to some extent during the course of product development because of improved understanding of the mechanism of action. The question is how far the specifications may diverge from the initial ones. A problem arises when the definition of the product/process has changed substan- 
tially. This is a key issue, and certainly one of the main difficulties encountered in CTP development: the relevance of the specifications may in fact rapidly become questionable and even obsolete because of dramatic changes in underlying scientific knowledge.

As an example, the two parameters 'quantity of cells' and 'viability' are evident, but the definition of a target phenotype as a function of the expected clinical effects is much more problematical, though potentially central in the product/process definition. Although functional testing may appear appropriate, functional assays may be rather complex to standardise and validate, and may require considerable skill to perform. It is noteworthy that major scientific questions regarding the potential efficacy of the CTP (such as cell homing, interaction with host tissue, etc.) are generally not taken into account at the start of clinical trials. In fact, in most cases, the approach to the development of autologous CTPs is essentially empirical.

The same quality requirements will apply whether these products are proprietary or nonproprietary medicinal products.

\section{The Problem of Ancillary Therapeutic Products}

The definition of an ATP is as follows: 'any product, with the exception of medical devices given in Article L.5211-1, which comes into contact with organs, tissues, cells or products from the human body or of animal origins during storage, preparation, transformation, packaging or transport before their therapeutic use in humans, and also any product that comes into contact with embryos during a medically assisted reproduction activity'.
Therefore, all the products used during a CT process will come under the definition of an ATP. This involves a large range of products, from the simple to the extremely complex.

Once the Decree on ATPs has come into force, manufacturers wanting to obtain a marketing authorisation for a new ATP will have to apply to Afssaps. The application is of course much 'lighter' than that for a new drug, but the dossier must provide sufficient guarantee with respect to in vitro safety, quality and efficacy of the ATP.

Subsequently, when applying for CTP market approval, the CTP manufacturer may refer to the ATP authorisation previously given by Afssaps. When the ancillary product has not yet been classified as an ATP at the time of CTP registration (or if Afssaps is in the process of evaluating the product), it becomes the responsibility of the CTP manufacturer to document the quality, the in vitro safety, and the efficacy of the ATP. Eventually, if the ATP has already been approved by Afssaps as a drug, a reference to the aforementioned approval will be sufficient.

Because the regulatory provisions dealing with ATPs are quite recent, it will probably take several years before an official list of approved ATPs is available. Therefore, the availability of ATPs of guaranteed quality, safety and efficacy may become a bottleneck for CTP development. As CT is not yet an established market, industrial players are not likely to be interested in specifically developing ATPs. For instance, the completion of some trials may depend on the supply of certain growth factors that are not currently available as approved drugs. To face this important problem, the first step will be to work with clinical trial sponsors to establish the list of ATP requirements, and to identify available products. In a second step, the production of some of the bio-

\begin{tabular}{|c|c|c|}
\hline $\begin{array}{l}\text { Pharmaceutical } \\
\text { companies }\end{array}$ & MA & $\begin{array}{l}\text { MA committee (exp. Gr) } \\
\text { Authorisation given } \\
\text { Europe MA possible } \\
\text { Pharmacovigilance }\end{array}$ \\
\hline $\begin{array}{l}\text { Proprietary } \\
\text { products }\end{array}$ & $\begin{array}{l}\text { Clinical trial } \\
\text { authorisation }\end{array}$ & $\begin{array}{l}\text { Group of experts } \\
\text { Adverse events }\end{array}$ \\
\hline \multirow{2}{*}{$\begin{array}{l}\text { Public or private } \\
\text { companies } \\
\text { Cell therapy } \\
\text { products }\end{array}$} & $\begin{array}{l}\text { Authorisation } \\
\text { for preparation of } \\
\text { cell therapy products }\end{array}$ & $\begin{array}{l}\text { CT/GT committee (exp.Gr) } \\
\text { Authorisation given } \\
\text { French authorisation } \\
\text { Biovigilance }\end{array}$ \\
\hline & $\begin{array}{l}\text { Clinical trial } \\
\text { authorisation }\end{array}$ & $\begin{array}{l}\text { Group of experts } \\
\text { Biovigilance }\end{array}$ \\
\hline
\end{tabular}

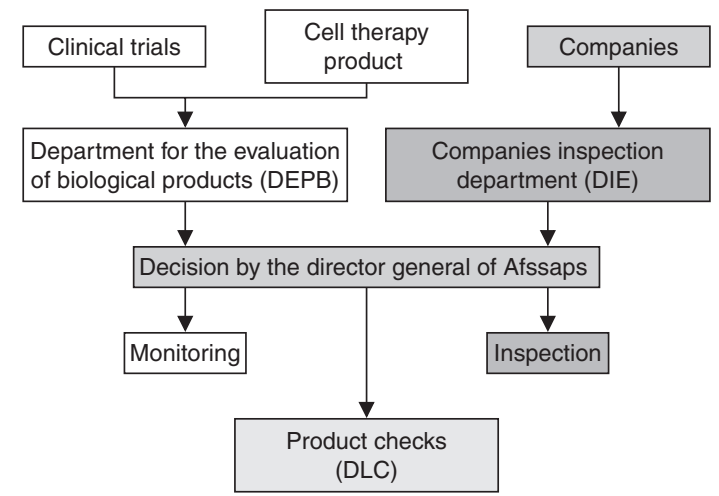

Fig. 2. Procedures set up by Afssaps (the French Health Products Safety Agency) depending on whether the cell preparations are proprietary products or nonproprietary products. $\mathbf{C T}=$ cell therapy; $\mathbf{D L C}=$ Laboratories and Controls Department; $\mathbf{e x p}$. $\mathbf{G r}=\operatorname{expert~group~} ; \mathbf{G T}=\mathrm{gene}$ therapy; $\mathbf{M A}=$ marketing authorisation. 
molecules could be mutualised and supported by public funding, maybe at the European level, at least until the market is mature enough to encourage commercial entities to handle ATP supply. In general, it is strongly recommended that a CTP clinical trial should not be engaged in if there are uncertainties about the supply of ATPs manufactured under GMP conditions.

\section{Nonclinical Development: Proof of Concept}

A fundamental distinction can be made regarding the preliminary proof of efficacy between immunotherapy, (primarily cancer immunotherapy) on the one hand, and tissue repair or gene transduction on the other hand. In immunotherapy, the major difficulty is the relevance of animal models in both therapeutic vaccination (e.g. using loaded dendritic cells) and in processes dealing with the administration of effector cells (e.g. macrophages, cytotoxic lymphocytes etc.). In adoptive immunotherapy settings, the cellular systems may be sufficiently conserved between species to allow for the use of syngeneic models. Conversely, the evaluation of the immunogenicity of cell preparations used in therapeutic vaccination to elicit the host immune response might be very difficult if not impossible because of interspecies differences. Significant progress is expected from the emergence of new transgenic animal models allowing evaluation of immunogenicity in a human MHC background. In contrast with the difficult situation encountered in immunotherapy, preclinical proof of concept might be easier to establish in tissue repair (hepatology, cardiology, myopathies, in particular), thanks to the availability of many relevant preclinical animal models.

Animal models play an important role in all therapeutic contexts, but they are particularly useful when assessing the route of administration for the CTP. Animal model experiments should in fact always be considered for this specific purpose.

\section{Nonclinical Development: Toxicology}

The risks that need to be evaluated are basically the same whether a CTP or a conventional medicinal product is being considered: single dose and repeated-dose toxicity, identification of target organs, toxicity to reproductive functions, mutagenicity or carcinogenicity, local tolerance and immunotoxicity. The regulatory provisions in force (Committee of Proprietary Medicinal Products [CPMP], International Conference on Harmonisation $[\mathrm{ICH}]$ etc.) cover these questions in great detail. However, the methods used to answer these questions when designing the development plan must take into account CTP specificities, in particular the availability of appropriate animal models. These studies must be performed using the actual CTP to be tested in clinics. Specific points should be considered: (i) the identification of the target organ must be carried out with an appropriate animal model, reflecting the clinical setting and taking into account the route of administration, the possible use of an implanted device etc.; (ii) when reinjected autologous cells produce in vivo a biologically active molecule (such as a cytokine or a growth factor, etc.), the toxicity of this biomolecule must be documented; and (iii) if the cell material used is likely to proliferate after reinjection, the carcinogenic risk must be carefully documented with several batches of CTP.

To conduct toxicology studies, as for other nonclinical studies, the CTP specifications must be defined, However, because a relevant animal model may not be available, and because, as mentioned earlier, CTP specifications may evolve throughout product development, a dialogue with the regulatory agency must be initiated as soon as possible. This dialogue is even more necessary for a CTP than for conventional products.

\section{Clinical Development}

The main question discussed was whether there was any methodological specificity in the clinical development of CTPs, and specifically whether the classical segmentation of the early exploratory phases into phase I clinical trials dedicated to tolerance studies and phase II clinical trials dedicated to clinical proof of concept did apply to cell therapy. The rationale of this segmentation was discussed at length, particularly for orphan indications without existing therapeutic alternatives. Clearly, clinical trial methodology needs to be discussed with regulatory agencies. Defining a maximum tolerated dose in a phase I clinical trial may be very difficult in cell therapy, and a case-by-case analysis is required. In cancer immunotherapy, given the very limited nonclinical information generally available, it seems preferable to perform a true phase I clinical trial with the principal objective of evaluating product safety. In this case, relevant biological data should of course be collected with adapted 'immunomonitoring' methods during tolerance studies. The problems posed by phase II clinical trials and efficacy studies are generally related to the size and heterogeneity of the patient groups in those trials, and particularly with respect to the definition of the control group. Cancer immunotherapy CTP poses specific problems, since patients treated in exploratory studies often have late-stage disease, with concomitant systemic immunosuppression. This population might not be equivalent to the patient population actually targeted by the CTP. Without questioning the general methodology of clinical development, this constraint emphasises the importance of immunomonitoring to obtain an accurate immunological characterisation of the populations tested. 
As for conventional products, phase III clinical trials must provide a statistical demonstration of the clinical efficacy of the CTP, and need to involve multicentre studies. Therefore, a problem specific to phase III trials is the control of the reproducibility of the CT manufacturing process and the distribution of CTP batches to the different sites. It was suggested that the most satisfactory way of dealing with such problems could be the centralisation of CTP manufacturing at a single site for a given process.

\section{Pharmacovigilance/Biovigilance}

The implementation of new regulatory provisions dealing with biovigilance will complete the regulatory provisions for the monitoring of other healthcare products (medicinal products and medical devices: in France, 'pharmacovigilance', 'matériovigilance' and 'réactovigilance'). A CTP used in a clinical trial or for a routine activity, as well as all ATPs used during these processes, will then come under the umbrella of this new biovigilance regulation. However, pharmacovigilance regulation will apply to CTPs that have been classified as proprietary medicinal products.

The group had some criticisms concerning the implementation of these new provisions, with regard to the increased complexity of the system and the related risks of misinterpretation by the industrial players (a CTP may or may not have the status of a proprietary medicinal product, while an ATP may have the status of a proprietary medicinal product). It is, however, recognised that the CTPs pose particular problems that are not addressed by the existing pharmacovigilance system, justifying the organisation of a dedicated system.

In addition, the group recommended that the implementation of the biovigilance regulatory provisions should be discussed as soon as possible with industry representatives and CT professionals.

\section{Recommendations/Actions}

The general recommendation is that the definition of product specifications, the development criteria for CTPs and the issues related to quality control should receive more consideration in trials conducted by academic institutions, so as to improve the quality and interpretation of the clinical data, and eventually facilitate the transfer of knowledge to the industry in later phases of product development.

Specific recommendations were as follows:

- to implement GMP principles at production sites;

- to increase the support for the protocols sponsored by the academia in regulatory affairs and QA;
- to initiate early discussions between the developers and the regulatory agency.

The working group also identified a number of issues and potential bottlenecks that may affect all players in CTP development: the current need for regulatory harmonisation at the European level, the uncertainties regarding the supply of ATPs, and the implementation of the biovigilance provisions. Consequently, following actions were also suggested:

- $\quad$ an inventory of ATP needs;

- the use of this inventory to initiate feasibility studies for collaborative production of ATPs, maybe at the European level, following the National Cancer Institute's (NCI) Rapid Access to Intervention Development (RAID) model;

- actions targeting harmonisation of European regulations such as the transposition of the directive 2001/83 for CTPs;

- the creation of a 'biovigilance working group' that includes pharmaceutical parties.

\section{Participants}

L. Becquemont (Pharmacology, Kremlin Bicêtre CHU), F. Bassompierre (DRC, AP-HP), B. Dreno (Inserm U463, Nantes), S. Lucas-Samuel (Afssaps, Thanks to K. Martinière, Afssaps), M. Pallardy (Inserm U461, Châtenay Malabry), S. Scholl (Institut Curie, Paris), M. Bonneville (Inserm, Nantes), P. Zorzi (Afssaps), E. Postaire (Coordinator, INSERM-DAPS Paris), P.-Y. Arnoux (Leem), I. Barilero (Johnson \& Johnson), E. Caugant (Wyeth, Paris), D. Debiais (Amgen, Neuilly/seine), M. Gersberg (Sanofi, Le Plessis Robinson), J. Tiollier (Innate Pharma, Marseille), H. Brailly (Innate Pharma, Marseille), H. Kabrane (Afssaps), J.-L. Romet-Lemonne (IDM), P. Squiban (Transgène), S. Solbès Latourette (AFM, Evry).

\section{References}

1. Law No. 94-654 of 29 July 1994 relating to donations and the use of human cells and products, medically assisted reproduction and prenatal diagnosis [online]. Available from URL: http://www.legifrance.gouv.fr/WAspad/UnTexteDeJorf?. numjo=SPSX9400032L [Accessed 2004 Jul 19]

2. Law No. 96-452 of 28 May 1996 on various health, social and legal measures [online]. Available from URL: http://www.social.gouv.fr/htm/minister/igas/ igas_loi3.htm [Accessed 2004 Jul 19]

3. Law No. 98-535 of 1st July 1998, relating to strengthening health surveillance and control of health safety of products for use in humans [online]. Available from URL: http://www.legifrance.gouv.fr/WAspad/UnTexteDeJorf?.numjo= MESX9702267L [Accessed 2004 Jul 19]

4. Decree No. 2001-909 of $1^{\text {st }}$ October 2001 relating to cells and genetic and cell therapy products fixing the authorisation conditions for establishments, organisations, processes, products and protocols for clinical trials and modifying the public health code [online]. Available from URL: http://www.arteb.com/infos/LoiDecrets/decret2001-909.pdf [Accessed 2004 Jul 19]

5. Order of 3 February 2003 fixing the contents of the dossier accompanying the request for authorisation of processes for the preparation, storage and transformation of cells and cell therapy products [online]. Available from URL: http://perso.club-internet.fr/dominique.mathis/bdlr/arr2000/A030203h.htm [Accessed 2004 Jul 19] 
6. Order of 3 February 2003 fixing the contents of the dossiers for the authorisation, renewal and modifications to the authorisation for establishments or organisations who prepare, store, distribute and transfer cells and genetic and cell therapy products which are not proprietary products or other drugs manufactured on an industrial scale [online]. Available from URL: http://perso.clubnternet.fr/dominique.mathis/bdlr/arr2000/A030203g.htm [Accessed 2004 Jul 19]

7. Order of 3 February 2003 relating to the conditions for the authorisation for implementing clinical trial protocols on human cells, cell therapy products and genetic therapy products [online]. Available from URL: http://perso.club-internet.fr/dominique.mathis/bdlr/arr2000/A030203f.htm [Accessed 2004 Jul 19]

Correspondence and offprints: Eric Postaire, INSERM-DAPS, 101 rue de Tolbiac, 75654 Paris Cedex 13, France.

E-mail: postaire@tolbiac.inserm.fr 